\title{
Exploring the suffix effect in serial visuospatial short-term memory
}

\author{
FABRICE B. R. PARMENTIER \\ University of Plymouth, Plymouth, England \\ SÉBASTIEN TREMBLAY \\ Université Laval, Québec City, Québec, Canada \\ and \\ DYLAN M. JONES \\ Cardiff University, Cardiff, Wales
}

\begin{abstract}
The suffix effect-the loss of recency induced by a redundant end-of-list item-was studied in a visuospatial serial recall task involving the memory for the position of dots on a screen. A visuospatial suffix markedly impaired recall of the last to-be-remembered dot. The impact on recall was roughly of equal magnitude whether the suffix shared attributes with the to-be-remembered dots (Experiment 1) or was visually distinct (Experiments 2 and 3). Although the presence of a tone suffix also impaired serial memory for the last items in the sequence, the impact of a visuospatial suffix was more marked, implying a specific as well as a possible general effect of suffix in the visuospatial domain (Experiment 4). The suffix effect seems not to be a phenomenon confined to verbal material but rather a universal phenomenon possibly related to grouping.
\end{abstract}

Memory for the order of items over the short term has been studied extensively, and a good deal is known about the key factors that govern the likelihood of correct recall. From the outset, interest has centered on the fact that the likelihood of recall varies over the length of the list. Relative to the middle of the list, recall is good for items at the beginning (a phenomenon known as primacy) and at the end (recency) of the list. Particular interest has been attached to the functional significance of variations in recency, especially with the modality of list presentation. Auditory verbal lists exhibit a very marked recency effect, whereas for visuoverbal lists, the recency effect is much less marked (see, e.g., Conrad \& Hull, 1968). However, this "modality" effect can be reduced by the introduction of a redundant item (a suffix) at the end of an auditory list. For some time it was thought that this suffix effect was peculiar to auditory lists, but recent research has shown that the effect may occur in a wide variety of settings.

This work was supported in the form of a project grant to D.M.J. from the Defence Evaluation \& Research Agency (Farnborough, Hampshire), Centre for Human Sciences, and by QR support from the University of Plymouth to F.B.R.P. Thanks are due Pilar Andrés, Caroline Cellard, Sophie Lamontagne, and Nick Mosdell for running the experiments and to Alistair Nicholls and Murray Maybery for their useful comments on an earlier draft of this article. Thanks are also due David Balota, Nelson Cowan, Catherine Penney, and Chris Miles for their comments during the reviewing process. Correspondence should be addressed to F. B. R. Parmentier, Department of Psychology, University of Plymouth, Drake Circus, Plymouth PL4 8AA, England (e-mail: fparmentier@ plymouth. ac.uk).
Since the earliest demonstrations of the suffix effect, it has been widely investigated (e.g., Baddeley \& Hull, 1979; Balota \& Engle, 1981; Beaman \& Morton, 2000; Crowder \& Morton, 1969; Greene, 1992; Greene \& Crowder, 1988; Nicholls \& Jones, 2002; Penney, 1985). Contemporary studies have shown that not only is marked recency not confined to the auditory verbal domain, it is also observed with visuoverbal material such as lipread lists (Campbell \& Dodd, 1982; Divin, Coyle, \& James, 2001; Gathercole, 1987) and, significantly, with visual nonverbal material, such as the position of objects in twodimensional space (e.g., Avons, 1998; Jones, Farrand, Stuart, \& Morris, 1995), or even with auditory spatial stimuli (Parmentier \& Jones, 2000). That suffix effects also appear in modalities other than the auditory has become evident. Suffix effects have been obtained with both tactile (e.g., Mahrer \& Miles, 1999) and olfactory (Miles \& Jenkins, 2000) sequences. Despite this extension of the scope of the suffix effect to nonverbal stimuli, suffix effects have not yet been demonstrated convincingly with visuospatial materials (see Frick, 1990, on the effect of the visual suffix effect, but using verbal stimuli). This study aims to redress this shortcoming.

The study of the suffix effect in visuospatial serial recall is interesting for what it may reveal about the processing of order in nonverbal domains. Within cognitive psychology generally, a sharp functional distinction has been drawn between verbal and nonverbal stimuli; it is commonly assumed that they draw upon different modules of processing resources (e.g., Baddeley, 1986; Hale, 
Myerson, Rhee, Weiss, \& Abrams, 1995; Logie, Zucco, $\&$ Baddeley, 1990). However, as more commonalities have been revealed between modalities, the strong form of this view has gradually eroded. This has meant that it is possible to entertain architectures other than the modular form and so a process-oriented view has gained ground instead, one in which there are shared processes but ones subject to constraints and affordances related to the structural limitations of the sense modalities in question.

In the present study, we examined the sensitivity of the recency effect for nonverbal visuospatial stimuli to the presence of a visuospatial suffix, using the dots task of Jones et al. (1995) as the primary task. In this task, participants are presented with dots in sequence, one at a time, identical save for their different spatial locations. Retention is tested immediately after presentation, when all dots are re-presented simultaneously in their original locations and the participants are required to mark them, using a mouse-driven pointer, in their order of presentation. Primacy and recency effects are found in such a task, but more noteworthy is that recency is of a magnitude approaching that found typically in auditory verbal serial recall tasks (Farrand \& Jones, 1996; Farrand, Parmentier, \& Jones, 2001; Jones et al., 1995). This suggests that marked recency is not a defining characteristic of auditory serial recall; a visuospatial task that requires serial recall may exhibit it also. The result thus suggests a functional similarity between visuospatial and auditory verbal tasks, and this may extend also to the key factor that modulates auditory recency - the suffix effect. The dots task in the following series of experiments constitutes a test of whether the suffix effect can be observed in visuospatial serial memory.

\section{EXPERIMENTS 1-4}

We explored the effect of a visuospatial suffix on a visuospatial list by presenting an extra dot at the end of to-be-remembered (TBR) sequences of dots. Participants were instructed to ignore the irrelevant additional stimulus and to remember the sequence of dots prior to the irrelevant item. In Experiment 1, an extra dot, the suffix, was presented in a fixed spatial location (center) and in the same color as the TBR dots. In Experiment 2, the suffix dot was presented in a fixed spatial location (center) but in a color distinct from that of the TBR dots (blue vs. black, respectively). In Experiment 3, the suffix dot was presented in a random spatial location and in a color distinct from that of the TBR sequence. In Experiment 4, the method of Experiment 2 was used but with the addition of a tone suffix condition (three conditions randomly intermixed). The rationale for these experiments was first to establish the presence of a suffix effect for sequences of visuospatial stimuli (Experiment 1); second, to investigate whether the perceptual distinctiveness of the suffix was an important factor and whether this might be related to grouping factors (Experiment 2); third, to determine whether the presentation of the suffix in an unpredictable spatial location would divert attention from the final TBR sequence item and hence make the attenuation of recency more marked (Experiment 3); and fourth, to establish how the visuospatial suffix effect compares with that of an auditory suffix (Experiment 4). In addition to the analysis of individual experiments, we compare the magnitude of the suffix effect across experiments. Since all experiments used a similar methodology, a unique description of the method is described below with specific details relative to each experiment highlighted.

\section{Method}

Participants. The numbers of participants were 20, 21, 20, and 35 in Experiments 1-4, respectively (different participants were used in each experiment). Students from Cardiff University (Experiments 1-3) and Laval University (Experiment 4) volunteered to take part in exchange for course credits. All reported normal or corrected-to-normal vision.

Material. A sequence of seven dots $0.85 \mathrm{~cm}$ in diameter was presented in different locations on a computer screen, one at a time, within a $17 \times 17 \mathrm{~cm}$ blank matrix. The coordinates for the dots' centers were randomly generated with the constraint that the centers of all dots taken two by two should be separated by at least $3 \mathrm{~cm}$ and at most $10.5 \mathrm{~cm}$. On each trial, a sequence of seven dots was displayed at a rate of one dot every second: $700 \mathrm{msec}$ on, $300 \mathrm{msec}$ off, with the latter being replaced by a 1,300-msec interval from the offset of the last to-be-remembered dot in the control condition (see below) or by an extra (irrelevant) dot presented in the suffix condition (see below). After the presentation phase, all dots were simultaneously re-presented in the spatial locations where they had originally been presented. The participants used a mouse to locate and click on the dots in the initial order in which they had sequentially been presented. To indicate to the participant that a response has been recorded, the color of a selected dot changed from black to green and remained that way until the end of the trial. Mouse clicks on a dot already selected did not produce this feedback, and to all intents and purposes the computer appeared inert in these cases.

Design and Procedure. In Experiments 1-3, two conditions were tested: a control condition and a suffix condition. Thirty trials were presented, 15 in each condition, the order of which was randomized with the restriction that no more than 3 trials of the same condition could be presented successively. In the control condition, all seven dots were presented in black color, whereas in the suffix condition, irrelevant to the memory task, a postsequence item was displayed in rhythm with the TBR series dots $(700 \mathrm{msec}$ on, $300 \mathrm{msec}$ off). The color and location of the suffix varied across experiments: same color as that of the TBR items at the center of the presentation matrix (Experiment 1); different color (blue) at the center of the presentation matrix (Experiment 2); different color (blue) in a random (different in every trial) spatial location (Experiment 3). The design of Experiment 4 was identical to that of Experiment 2 with the addition of a third condition (15 trials) in which a tone suffix ( $700 \mathrm{msec}$ long, $230 \mathrm{~Hz}$ tone) was presented over headphones. The time separating the offset of the last to-be-remembered dot from the time of recall was the same in the control and suffix conditions in all experiments. The participants were told that the irrelevant dot (Experiments 1-4) or suffix (in Experiment 4), when presented, should be ignored. In all conditions, at recall, only the seven TBR dots were re-presented as filled (black) circles.

The participants were seated approximately $50 \mathrm{~cm}$ from the computer screen on which the visuospatial task was displayed. Written instructions encouraged them to respond as quickly and accurately as possible and informed them that once an item had been selected, it could not be altered. One practice trial per condition was presented in each experiment (i.e., two in Experiments 1-3, three in 
Experiment 4, all in random order). The presentation of trials was self-paced; the participants mouse-clicked on a button display to initiate a trial. Following the presentation of the stimulus sequence, the seven TBR dots were re-presented simultaneously, which prompted the participants to start recalling them in order. The participants were tested individually, and the experiment took 20-25 min. The responses were scored automatically with respect to serial position and condition.

\section{Results and Discussion}

Responses were scored according to a strict serial recall criterion. The mean number of correct responses at each serial position and for the control and suffix conditions is depicted in Figure 1. The dot suffix affected recall of the last to-be-remembered item in all of the ex- periments. In Experiment 4, the tone suffix produced some disruption but less than the dot suffix did.

Here we report a general analysis of the serial position curves as well as three measures of recency to evaluate specifically the effect of the suffix. This follows the precedent of Nicholls and Jones (2002), who pointed out that previous studies have varied in how recency was measured and that comparisons across investigations can therefore be difficult. The three measures of recency were (1) an absolute recency measure, comparing absolute accuracy performance in the suffix and control conditions at the last serial position; (2) a relative recency measure, comparing the relative increase in accuracy performance from the penultimate serial position to the last for the
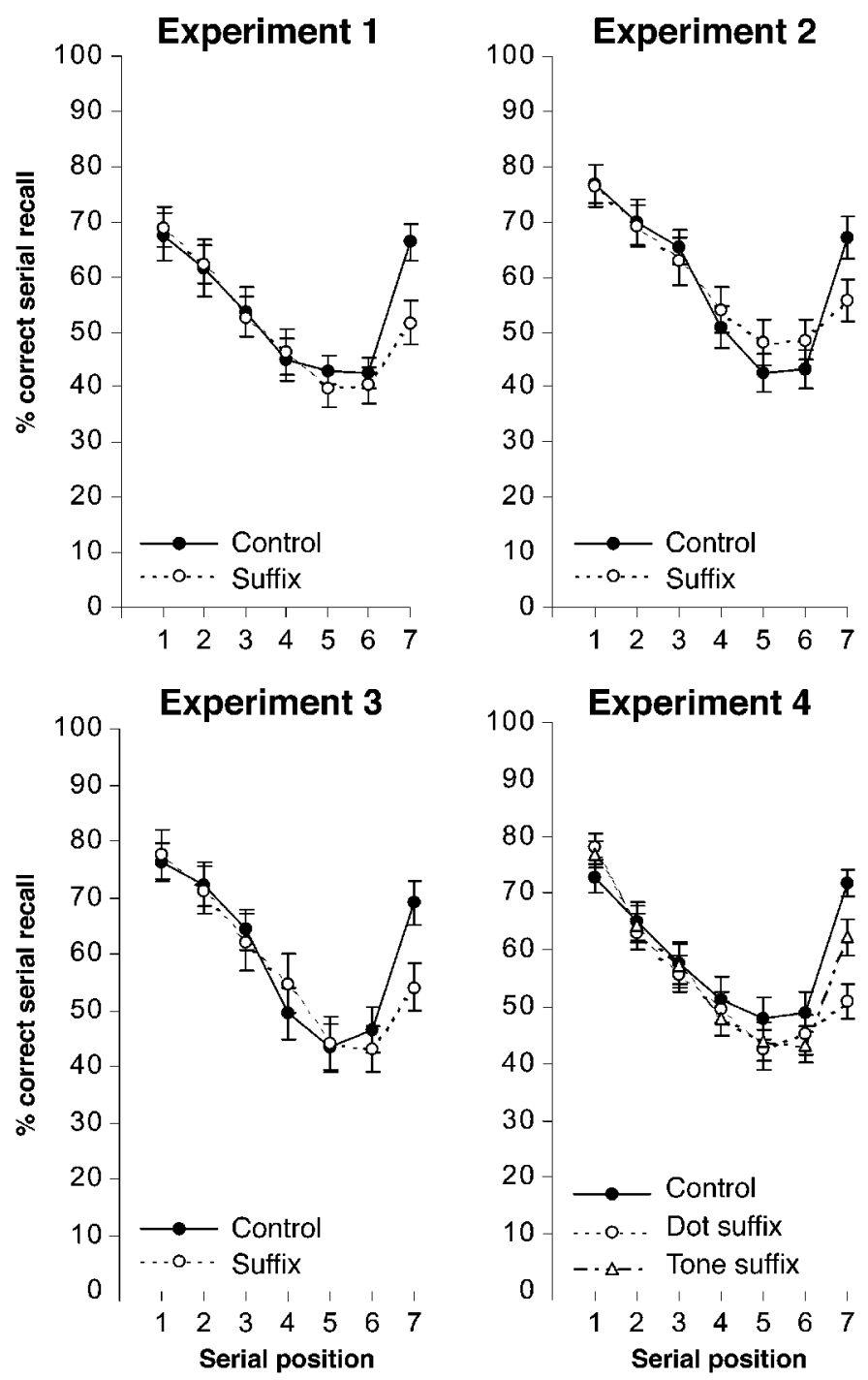

Figure 1. Experiments 1, 2, 3, and 4: Mean percentage of correct responses as a function of serial position for the control and suffix conditions. Error bars represent standard error. 
suffix and control conditions; and (3) a normalized recency measure, calculated as the proportion of accuracy performance at the last serial position on the sum of accuracy performance across all serial positions, again for the suffix and control conditions.

To simplify the presentation of the results, only significant differences are reported.

Analysis of serial position curves. The number of correct responses was analyzed using condition (2: Experiments 1-3, or 3: Experiment 4) $\times$ serial position (7) analyses of variance (ANOVAs) for repeated measures. The pattern of results was strikingly clear and similar across experiments. The main effect of condition was not significant in any of the experiments, whereas a significant effect of serial position was found in all $[F(6,114)=$ $23.60, M S_{\mathrm{e}}=4.25, p<.001($ Experiment 1$) ; F(6,120)=$ $36.70, M S_{\mathrm{e}}=3.69, p<.001($ Experiment 2$) ; F(6,114)=$ 41.87, $M S_{\mathrm{e}}=3.58, p<.001$ (Experiment 3); and $F(6,204)=49.24, M S_{\mathrm{e}}=6.35, p<.001($ Experiment 4$\left.)\right]$. More important, a significant condition $\times$ serial position interaction was found in all experiments $[F(6,114)=2.30$, $M S_{\mathrm{e}}=3.14, p<.05($ Experiment 1$) ; F(6,120)=3.02$, $M S_{\mathrm{e}}=2.68, p<.01$ (Experiment 2$) ; F(6,114)=3.60$, $M S_{\mathrm{e}}=2.55, p<.05$ (Experiment 3$)$; and $F(12,408)=$ $5.28, M S_{\mathrm{e}}=2.21, p<.001$ (Experiment 4 )]. The twoway interactions were analyzed using simple main effects between the control and suffix conditions at Serial Positions 1-6. Performance at Serial Position 7 was the object of particular analyses (see below). Again the pattern of data was very clear: No difference between the control and suffix conditions was found at any serial position (1-6) in Experiments 1-4.

Measures of recency. The negative effect of the dot suffix on memory for the last TBR dot was confirmed in all four experiments with all measures of recency (absolute, relative, and normalized), as measured with onetailed $t$ tests. Experiment 4 also revealed that the tone suffix reduced performance relative to the control condition (with the absolute and normalized measures of recency), but significantly less so than the dot suffix (with all measures of recency). The detail of these comparisons is illustrated in Figure 2.

\section{Joint Analysis of Recency for Experiments 1, 2, and 3}

As Experiments 1-3 shared the same experimental design and differed only in the extent to which the suffix dot differed from the TBR dots, a joint analysis was carried out on the recency measures in order to establish whether the size of the suffix effect observed in Experiments $1-3$ was equivalent. Separate 3 (experiment) $\times 2$ (suffix vs. control) ANOVAs were carried out for each of the measures of recency reported above. Levels of recency for the control and suffix conditions for all experiments reported in this study are illustrated in Figure 2. The results of the analysis were similar with all three measures of recency: Only the main effect of suffix was significant $\left[F(2,58)=27.79, M S_{\mathrm{e}}=205.84, p<.001\right.$ (absolute); $F(2,58)=31.51, M S_{\mathrm{e}}=179.13, p<.001$ (relative); and $F(2,58)=32.94, M S_{\mathrm{e}}=10.42, p<.001$ (normalized)]. No significant main effect of experiment or interaction between experiment and the suffix condition was found.

\section{GENERAL DISCUSSION}

The results of Experiment 1 indicate that the presence of a suffix item presented in a predictable location significantly impaired recall of the last item. In the verbal domain, when the suffix differs from the TBR on some perceptual dimension, the effect of that suffix is attenuated. For example, Morton, Crowder, and Prussin (1971) showed that a change of voice or spatial location between the TBR items and the suffix reduces the suffix effect (see also Balota \& Engle, 1981; Crowder \& Morton, 1969; LeCompte \& Watkins, 1995; Watkins \& Watkins, 1980). These studies suggest that a perceptual change reduces the disruptive potency of the suffix. In Experiment 2 , however, a suffix dot in a color different from that of the TBR dots produced a suffix effect similar to that of Experiment 1, for all measures of recency examined. Interestingly, the suffix effect was not amplified by using a spatially unpredictable suffix either (Experiment 3). Overall, the visuospatial suffix effect reported above appeared stable and unaffected by changes in the visual and spatial characteristics of the suffix.

Experiment 4 was conducted in order to establish to what extent the suffix effect was due to nonspecific (supramodal) distraction or selective disruption of visuospatial serial memory. Although the tone affected recency relative to the control condition, the presentation of a dot suffix was significantly more disruptive for all measures of recency. Although the effect of the tone suffix may partly have been the result of attentional distraction or spatial interference (a tone does have a spatial locus), a selective visuospatial negative effect was clearly observed.

Taken together, the results of the four experiments indicate that visuospatial serial memory is subject to the suffix effect. Although the suffix effect has been examined repeatedly in the verbal literature (e.g., Bloom \& Watkins, 1999; Crowder \& Morton, 1969; Penney, 1985; Watkins \& Watkins, 1980), aside from the present study we are not aware of any investigation directly examining the suffix effect in visuospatial serial memory. The suffix effect found in our experiments adds to the increasing evidence pointing out the functional similarities of verbal and nonverbal memory (Avons, 1998; Avons \& Masson, 1999; Farrand \& Jones, 1996; Jones et al., 1995), insofar as recency for visuospatial items was affected by a suffix of the same modality.

However, an important distinctive feature of the results of the present study is that manipulation of the visuospatial attributes of the suffix-particularly its similarity to the to-be-remembered list-does not reduce the suffix effect, contrary to what is typically found in verbal studies (e.g., Crowder \& Morton, 1969). The dis- 

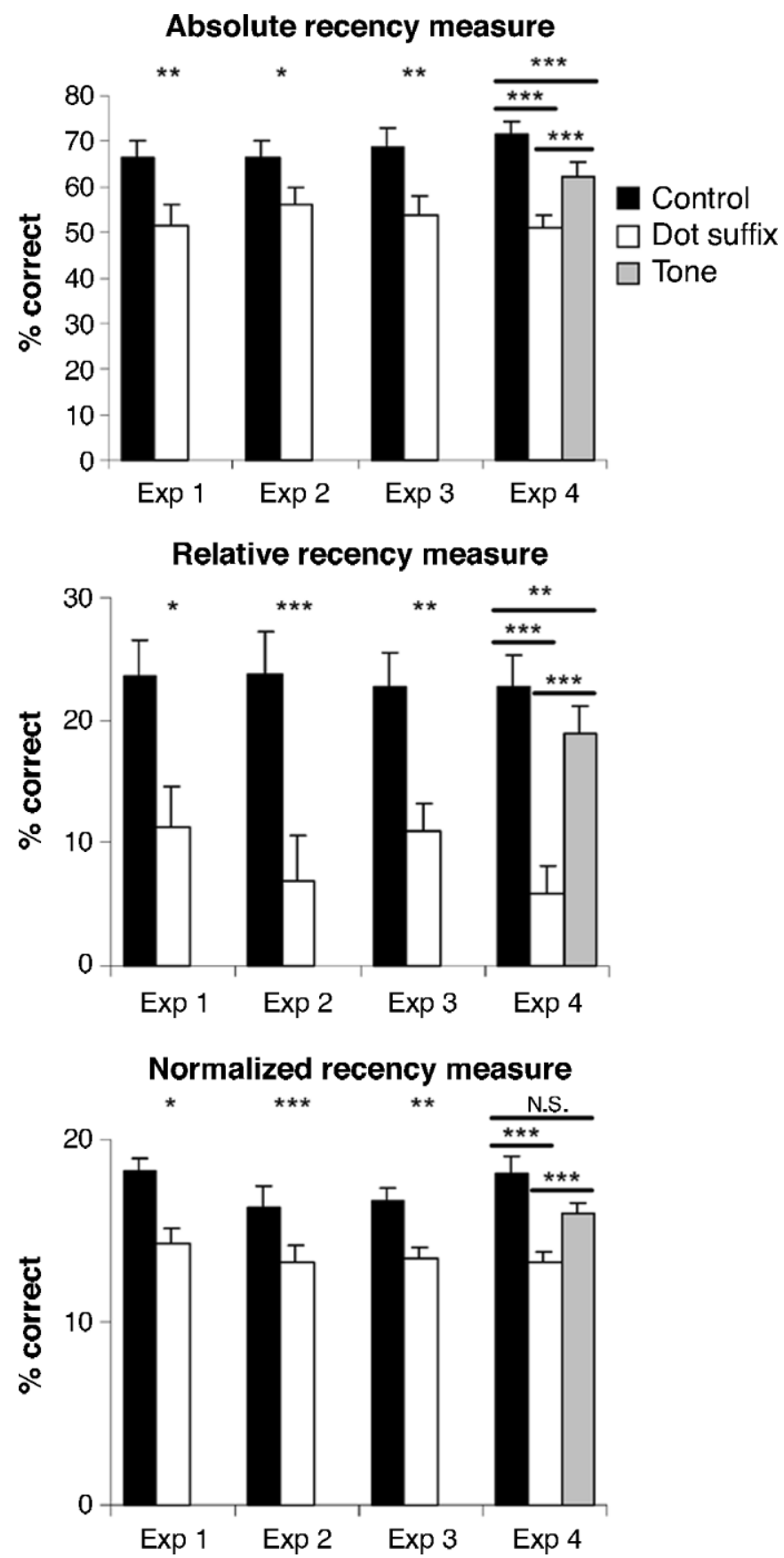

Figure 2. Experiments 1, 2,3, and 4: Mean percentage correct for the absolute (top panel), relative (middle panel), and normalized (bottom panel) recency measures. Error bars represent standard error. * $p<$ $.05 . * * p<.01$. $* * * p<.001$. N.S., nonsignificant difference.

crepancy between our results and those reported in verbal studies suggest that the visuospatial suffix effect might rely on processes at least partly different from those dictating the suffix effect in verbal serial recall tasks.

As has recently been pointed out by Nicholls and Jones (2002), the verbal literature on the suffix effect presents two major theoretical perspectives: the masking account and the grouping account. According to the masking account, serial recall performance for the last item of a TBR sequence is overwritten by the presentation of the suffix (e.g., Nairne, 1990). From the grouping point of view, the suffix becomes part of the same cohort as the TBR items; that is, it is grouped with the TBR items 
(Frankish, 1989; Nicholls \& Jones, 2002). The data of Nicholls and Jones clearly favor the grouping account, because they demonstrate that the suffix effect can be moderated by the extent to which the suffix can be segregated from the to-be-remembered items on the basis of auditory streaming (Bregman, 1990). With regard to the data reported in the present study, the grouping hypothesis does not seem to extend to visuospatial serial memory, however. Indeed, the identical suffix effects found in Experiments 1-3 suggest that an irrelevant visuospatial stimulus is not easier to ignore if it is visually distinctive from the to-be-remembered stimuli than if it is not, which suggests that visual distinctiveness does not, in the context of these experiments, lead to the suffix being perceived as segregated from the TBR items. The masking hypothesis is not particularly convincing either, because it would predict that the suffix effect should increase as the suffix and the TBR stimuli share more features (see the feature model for the latest formulation of this idea: Nairne, 1990). In the present context, this implies that the suffix in Experiment 1 should have been more damaging than that in Experiment 2 or 3, because the first shared a visual feature with the TBR items that the second did not (i.e., color).

A possible source of disruption that is specific to visuospatial serial memory is shifts of spatial attention. Evidence indicates that the abrupt onset of visual information mobilizes attention (Remington, Johnston, \& Yantis, 1992; Yantis \& Jonides, 1984). Evidence also suggests that serial visuospatial short-term memory is disrupted by tasks involving spatial judgments or automatic shifts of spatial attention (Smyth \& Scholey, 1994) independently of eye movements (Smyth, 1996). Interestingly, it has also been suggested that the involvement of focal attention can explain the suffix effect observed with visually presented verbal stimuli (Hitch, 1975). In addition, the view that spatial rehearsal and spatial attention overlap has been reinforced by the demonstration that both functions share a common neuroanatomical substrate (Awh \& Jonides, 1998, 2001; Awh et al., 1999). It may be hypothesized that, in our experiments, the mere presentation of the suffix attracted participants' spatial attention to the suffix location, regardless of the color or location of the suffix, and that this movement of attention may have been responsible for disrupting the maintenance of the last TBR item encoded. The hypothesis of a capture of spatial attention implies that the color of the suffix becomes irrelevant, because, by the time the color of the suffix is processed, spatial attention has already been captured by the suffix. In other words, if participants remember sequences of locations as spatial relationships between subsequent locations rather than as a sequence of spatial coordinates, then the movement of spatial attention from the last to-be-remembered locations to the suffix location would interfere with the memory of the preceding spatial attention movement (between the penultimate and the ultimate to-be-remembered locations), regardless of the visual properties of the suffix.
In conclusion, in this study we have reported similar visuospatial suffix effects in four experiments using suffixes presenting different visuospatial characteristics. This constitutes the first demonstration of the existence of a suffix effect in visuospatial serial memory, and it provides further evidence accumulating against any simple notion of modular partitioning of spatial and verbal short-term memory. Although the mere presentation of a suffix may distract participants or capture their spatial attention (any suffix, even a tone, has a spatial locus), at least part of the suffix effect that we have reported seems to be related to the visuospatial nature of the suffix and the memory task. These results present implications both for the understanding of visuospatial serial memory and the study of the suffix effect, and further research is needed in order to explore factors modulating the suffix effect in visuospatial serial memory and to compare its underlying determinants with those observed in other domains (verbal, e.g., Nicholls \& Jones, 2002; tactile, e.g., Mahrer \& Miles, 1999; olfactory, e.g., Miles \& Jenkins, 2000). The results still leave open the question of whether different memory systems are required for spatial material and for verbal material; the evidence presented here suggests that there are many common factors and that the differences can be explained by the functional peculiarities of the perceptual processing of stimuli rather than by mnemonic systems per se.

\section{REFERENCES}

Avons, S. E. (1998). Serial report and item recognition of novel visual patterns. British Journal of Psychology, 89, 285-308.

AVONS, S. E., \& MASON, A. (1999). Effects of visual similarity on serial report and item recognition. Quarterly Journal of Experimental Psychology, 52A, 217-240.

AWH, E., \& JONIDES, J. (1998). Spatial selective attention and spatial working memory. In R. Parasuraman (Ed.), The attentive brain (pp. 353-380). Cambridge, MA: MIT Press.

AWH, E., \& JonIDES, J. (2001). Overlapping mechanisms of attention and spatial working memory. Trends in Cognitive Sciences, 5, 119126.

Awh, E., Jonides, J., Smith, E. E., Buxton, R. B., Frank, L. R., Love, T., WonG, E. C., \& GMEINDL, L. (1999). Rehearsal in spatial working memory: Evidence from neuroimaging. Psychological Science, 10, 433-437.

BADDELEy, A. [D.] (1986). Working memory. Oxford: Oxford University Press.

Baddeley,A. D., \& Hull, A. (1979). Prefix and suffix effects: Do they have a common basis? Journal of Verbal Learning \& Verbal Behavior, 18, 129-140.

BALOTA, D. A., \& ENGLE, R. W. (1981). Structural and strategic factors in the stimulus suffix effect. Journal of Verbal Learning \& Verbal Behavior, 20, 346-357.

Beaman, C. P., \& Morton, J. (2000). The effects of rime on auditory recency and the suffix effect. European Journal of Cognitive Psychology, 12, 223-242.

Bloom, L. C., \& Watkins, M. J. (1999). Two-components theory of the suffix effect: Contrary findings. Journal of Experimental Psychology: Learning, Memory, \& Cognition, 25, 1452-1474.

Bregman, A. S. (1990). Auditory scene analysis: The perceptual organization of sound. Cambridge, MA: MIT Press.

CAmpbell, R., \& DodD, B. (1982). Some suffix effects on lipread lists. Canadian Journal of Psychology, 36, 508-514.

ConRaD, R., \& Hull, A. J. (1968). Input modality and the serial position curve in short-term memory. Psychonomic Science, 10, 135-136. 
Crowder, R. G., \& Morton, J. (1969). Precategorical acoustic storage (PAS). Perception \& Psychophysics, 5, 365-373.

Divin, W., COYLE, K., \& JAMES, D. T. T. (2001). The effects of irrelevant speech and articulatory suppression on the serial recall of silently presented lipread digits. British Journal of Psychology, 92, 593-616.

FARRAND, P., \& JONES, D. M. (1996). Direction of report in spatial and verbal serial short-term memory. Quarterly Journal of Experimental Psychology, 49A, 140-158.

FARRAND, P., PARMEnTIER, F. B. R., \& Jones, D. M. (2001). Temporalspatial memory: Retrieval of spatial information does not reduce recency. Acta Psychologica, 106, 285-301.

FRANKISH, C. F. (1989). Perceptual organization and precategorical acoustic storage. Journal of Experimental Psychology: Learning, Memory, \& Cognition, 15, 469-479.

FRICK, R. W. (1990). The visual suffix effect in tests of the visual shortterm store. Bulletin of the Psychonomic Society, 28, 101-104.

GATHERCOLE, S. E. (1987). Lip-reading: Implications for theories of short-term memory. In D. Dodd \& R. Campbell (Eds.), Hearing by eye (pp. 247-241). Hillsdale, NJ: Erlbaum.

Greene, R. L. (1992). Human memory: Paradigms and paradoxes. Hillsdale, NJ: Erlbaum.

Greene, R. L., \& Crowder, R. G. (1988). Memory for serial position: Effects of spacing, vocalization, and stimulus suffixes. Journal of Experimental Psychology: Learning, Memory, \& Cognition, 14, 740748.

Hale, S., Myerson, J., Rhee, S. H., Weiss, C. S., \& Abrams, R. A. (1995). Selective interference with the maintenance of location information in working memory. Neuropsychology, 10, 228-240.

Hitch, G. J. (1975). The role of attention in visual and auditory suffix effects. Memory \& Cognition, 3, 501-505.

Jones, D., FARrand, P., StuART, G., \& Morris, N. (1995). Functional equivalence of verbal and spatial information in serial short-term memory. Journal of Experimental Psychology: Learning, Memory, \& Cognition, 21, 1008-1018.

LeCoMPTE, D. C., \& WATKINS, M. J. (1995). Grouping in primary memory: The case of the compound suff ix. Journal of Experimental Psychology: Learning, Memory, \& Cognition, 21, 96-102.

Logie, R. H., Zucco, G. M., \& BAdDELEy, A. D. (1990). Interference with visual short-term memory. Acta Psychologica, 75, 55-74.
MAhrer, P., \& Miles, C. (1999). Memorial and strategic determinants of tactile recency. Journal of Experimental Psychology: Learning, Memory, \& Cognition, 25, 630-643.

Miles, C., \& Jenkins, R. (2000). Recency and suffix effects with immediate recall of olfactory stimuli. Memory, 8, 195-206.

Morton, J., Crowder, R. G., \& Prussin, H. A. (1971). Experiments with the stimulus suffix effect. Journal of Experimental Psychology, 91, 169-190.

NAIRNE, J. S. (1990). A feature model of immediate memory. Memory \& Cognition, 18, 251-269.

Nicholls, A. P., \& JONES, D. M. (2002). Capturing the suffix: Cognitive streaming in immediate serial recall. Journal of Experimental Psychology: Learning, Memory, \& Cognition, 28, 12-28.

PARMentier, F. B. R., \& Jones, D. M. (2000). Functional characteristics of auditory temporal-spatial short-term memory: Evidence from serial order curves. Journal of Experimental Psychology: Learning, Memory, \& Cognition, 26, 222-238.

PenNey, C. G. (1985). Elimination of the suffix effect on preterminal list items with unpredictable list length: Evidence for a dual model of suffix effects. Journal of Experimental Psychology: Learning, Memory, \& Cognition, 11, 229-247.

Remington, R. W., Johnston, J. C., \& YAntis, S. (1992). Involuntary attentional capture by abrupt onsets. Perception \& Psychophysics, 51, 279-290.

SмYтH, M. M. (1996). Interference with rehearsal in spatial working memory in the absence of eye movements. Quarterly Journal of Experimental Psychology, 49A, 940-949.

Smyth, M. M., \& SCHOLEY, K. A. (1994). Interference in immediate spatial memory. Memory \& Cognition, 22, 1-13.

WATKIns, O. C., \& WATKIns, M. J. (1980). The modality effect and echoic memory. Journal of Experimental Psychology: General, 109, 251-278.

YANTIS, S., \& JONIDES, J. (1984). Abrupt visual onsets and selective attention: Evidence from visual search. Journal of Experimental Psychology: Human Perception \& Performance, 10, 601-621.

(Manuscript received December 12, 2002; revision accepted for publication March 17, 2003.) 